\title{
Steel-concrete Composite Material in CNC Machine Tool Structures
}

\author{
Dominik Hermansky ${ }^{1, *}$, Jiri Marek ${ }^{2}$ \\ 'Intemac Solutions, s.r.o., Blanenska 1288/27, 66434 Kurim, Czech Republic \\ ${ }^{2}$ TOS Kurim - OS, a.S., Blanenska 1321/47, 66434 Kurim, Czech Republic
}

\begin{abstract}
The paper proposes a brief approach to utilization of steel-concrete composite in machine tool structures. It presents the possibility of replacing conservative solutions in machine frames based on traditional metallic materials like a gray cast iron or a steel. First part of the paper is focused on determining a whole spectrum of influences, that are must be taken into account during the design stage of machine tool supporting structure. Materials and topology optimization of machine frames are described in the next section of the article. The main part of paper deals with new concept of machine tool structure material. Namely steel-concrete composite developed in order to increase dynamic parameters of machine tool.
\end{abstract}

Keywords: machine tool, structure, steel, concrete, composite, dynamics.

\section{Introduction}

The frame structure of machine tool is one of the most important components inside the machine system. Supporting structures have to ensure fixed geometric configuration of machine under static and dynamic loads. Nonnegligible influences come from thermal sources, so thermal conditions during machining process must be considered during the design stage of machine structures [1].

While designing a supporting structure, the designer must respect many points of view which can be summarized in some essential and generally valid requirements as the following ones are:

application of the top quality material for the frame [5];

- good static rigidity;

- sufficient dynamic and temperature stability;

- to enable good chip removal;

- simple and efficient manufacture;

- small weight;

- easy manipulability;

a good installation on the foundation [2].

\section{Influences affecting machine tools structure parameters}

Moreover, some essential questions will be discussed which must be taken into consideration to comply with the mentioned requirements. It is the right place to declare that the information mentioned in the following text must be assessed at the particular application in comprehensiveness of all conditions varying in the particular cases, which is conditioned by specific machine tool operation. 
Properties of parts and assembly groups of CNC machine tools are determined mainly by:

\section{a) the material;}

b) topology - shaping, ribbing, wall thickness, proportions of parts;

c) connections - the quantity, position and type execution of fixed connections and movable connections.

The manufacturer and the designer can influence all of these properties to a certain extent. However, there are many limitations here. For example, these are cost limitations. It is clear that it is not always possible to use that possibility or variant which is the most suitable one in its technical aspect, but it is necessary to select such a possibility or variant which has adequate costs.

Other limitations are often very complicated optimization processes leading to improvement and increase of machine parameters. In many cases the application of these advanced optimization methods requires not only great demands on developers but it also requires costs on commercial calculation systems enabling to perform optimization. Due to this, the conservative solution is often selected to avoid unexpected complications and uncertainties, not the optimum solution or the solution which is very close to the optimum one.

\subsection{Materials}

It is possible to use various materials for the design of the machine tool supporting structure, grey cast iron, steel and cast steel are most often used, but lately also various nonferrous materials, especially concrete and polymere concrete have been used to a still greater extent.

While selecting the material kind, it is always necessary to assess especially the essential physical properties of the particular material which directly influence the specific technical and operation machine properties (Tab.1). The material must have these important properties:

- high rigidity and strength (safety against permanent deformation and breakage);

- low weight (static and dynamic properties);

- high damping of vibrations (dynamic properties);

- low internal stress (long term accuracy);

- low thermal dilatability (thermal stability);

- low energetic costs for material acquisition;

- low material costs [2].

As it can be seen from the above mentioned facts, the requirements are often contradictory ones. The mechanism of the physical damping principle is very complicated and it is still the subject of research. From the technical point of view, it is possible to state that high values of internal damping can be found especially at materials composed of more macroscopic phases or at materials with many internal interfaces among the particular components.

From this point of view, the following materials are important ones: fibre or particle composites, materials containing foamy filling or macroscopic combinations of these materials with conventional materials based on Fe-C designated as hybrid structures [2].

Table 1: Physical properties of materials for supporting structures [2].

\begin{tabular}{|c|c|c|c|c|c|c|c|c|c|c|}
\hline & & & & & \multicolumn{6}{|c|}{ Fibre composites with epoxy resin } \\
\hline & \multicolumn{2}{|c|}{ Metallic materials } & \multicolumn{2}{|c|}{ Particle composites } & \multirow{2}{*}{ 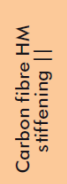 } & \multirow{2}{*}{ 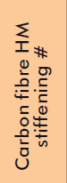 } & \multirow{2}{*}{ 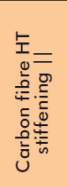 } & \multirow{2}{*}{ 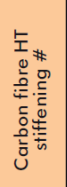 } & \multirow{2}{*}{ 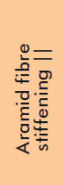 } & \multirow{2}{*}{ 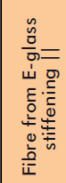 } \\
\hline & Steel & Cast iron & $\begin{array}{l}\text { Polymere } \\
\text { concrete }\end{array}$ & HPC concrete & & & & & & \\
\hline Specific weight $\left[\mathrm{kg} \cdot \mathrm{m}^{-3}\right]$ & 7850 & 7200 & $2300-2500$ & $2200-2500$ & 1600 & 1600 & 1600 & 1600 & 1400 & 2000 \\
\hline Poisson's ratio $[-]$ & 0,3 & $0,2-0,3$ & $0,25-0,3$ & $0,2-0,3$ & - & - & - & - & - & - \\
\hline E-modulus [GPa] & 210 & $70-10$ & $30-44$ & $50-60$ & 360 & 120 & 144 & 48 & 50 & 40 \\
\hline Tensile strength [MPa] & $400-1600$ & $150-400$ & $10-40$ & $8-10$ & 1200 & 400 & 2400 & 800 & 200 & 1100 \\
\hline Compression strength [MPa] & $250-1200$ & $700-1200$ & $140-160$ & $100-200$ & - & - & - & - & - & - \\
\hline Bending strength $[\mathrm{MPa}]$ & $150-600$ & $100-300$ & $15-50$ & $3-8$ & - & - & - & - & - & - \\
\hline Damping decrement [-] & 0,002 & 0,003 & $0,02-0,03$ & $0,02-0,03$ & - & - & - & - & - & - \\
\hline Coefficient of linear expansion $\left[10^{-6} / \mathrm{K}\right]$ & $11-18$ & 10 & $9-18$ & 10,6 & $-0,5$ & -1 & 0 & 0,5 & $-3,5$ & 5 \\
\hline Thermal conductivity $\left[\mathrm{Wm}^{-1} \mathrm{~K}^{-1}\right]$ & $47-$ & 50 & $1-3$ & 1,7 & 50 & 1 & 10 & 1 & 0,1 & 0,6 \\
\hline Specific heat capacity [ $\left.\mathrm{KJkg}^{-1} \mathrm{~K}^{-1}\right]$ & 0,49 & 0,45 & $0,7-1,3$ & 0,9 & 1 & 1 & 1 & 1 & 1,5 & 1,1 \\
\hline
\end{tabular}




\subsection{Topology}

After the material choice topology design of structural components is needed. At first stage of development engineers can utilize many researches that are done. For instance in [3] are described different types of ribs and evaluated displacements when bending load is applied (Figure 1). Ribbing principles are given for a lightweight steel structure.

To improve different properties like stiffness increasing or mass reducing topology optimization can be performed. Optimizations are generally based on numerical methods, namely Finite Element Method is popular. Many approaches for topology optimization are reviewed in [4].
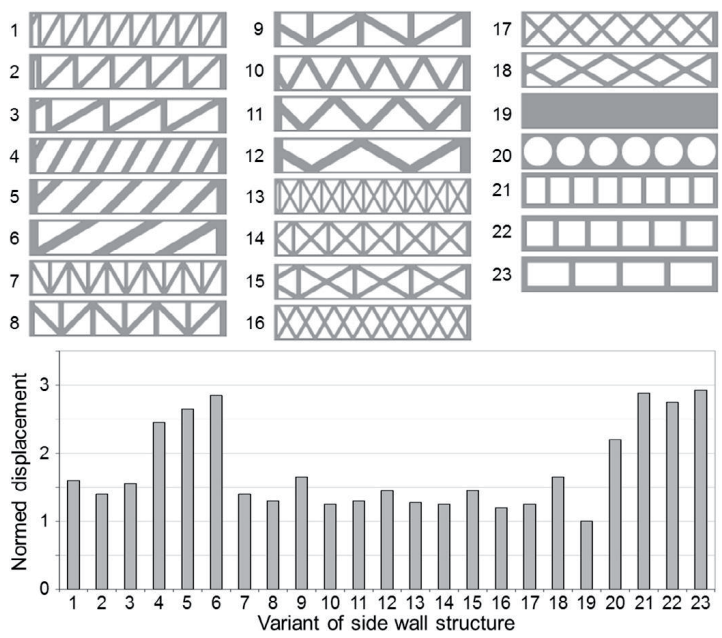

Fig. 1: Different wall constructions for welded steel constructions [3].

\section{Steel-concrete composite}

In cooperation of TOS Kurim and research organization for product machines Intemac Solutions steel-concrete structures developed for a purpose replacing gray cast iron in machine tools structures. Special concrete dedicated for steelconcrete frames and machine beds is classified in HSC category (High Strength Concrete).

There are some discrepancies in notion. Steelconcrete composite material always remains from welded steel profiles filled with concrete. Concrete has high strength and makes the structure more compact. Connecting steel components with high tensile strength and high-strength concrete enables lightening of cross-sections and increases carrying capacity under bending and eccentric loads.

Next advantage of mentioned composite is economic aspects. Utilization of a steel structure filled with a concrete began about 15 years ago. Otherwise term "reinforced concrete" hides concrete with steel armature within. Connection of a steel beam with concrete is approximately 110 years old. In that time iron-concrete constructions have begun. General requirements of mechanical properties for high strength concrete in steelconcrete structures:

\section{- minimal compressive strength - $80 \mathrm{MPa}$;}

- minimal tensile strength in bending - $6 \mathrm{MPa}$;

- minimal static modulus of elasticity - $40 \mathrm{GPa}$;

- minimal negative changes in volume, total shrinkage of concrete should not exceed $0,5 \mathrm{~mm} / \mathrm{m}$.

\section{Conclusions}

Prototype of a machining center with a movable column were built and presented at EMO 2016 in Milan. Machine tool frame structure is made of steel-concrete composite material. Fig. 2 shows machine bed made of steel welded structure filled with high strength concrete.

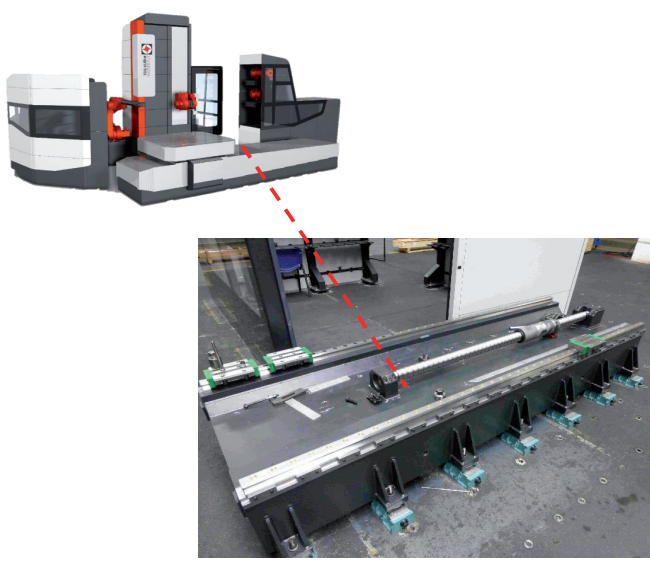

Fig. 2: Machine bed made of steel-concrete composite.

\section{Modal analysis}

For the purpose of verifying steel-concrete composite parameters modal analysis was performed. At Fig. 3 is shown spectrum of natural frequencies of machine bed. Upper image represents modal analysis of welded frame before filling with concrete. Subsequently lower image describes changes in modal characteristics. 


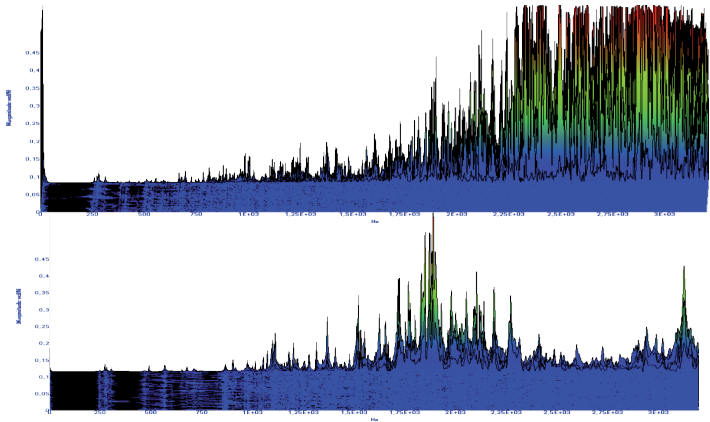

Fig. 3: Modal characteristics of machine.

\section{Dynamic stiffness}

Dynamic stiffness is the most powerful parameter for evaluating machine tool quality. In physical manner dynamic stiffness is obtained from frequency response. Frequency response contains natural frequencies and magnitudes of amplitudes at these frequencies. Dividing real part of amplitude by driving force dynamic stiffness is evaluated. Sometimes it is more comfortable evaluate in term "dynamic compliance" (1/dynamic stiffness). It is not reasonable perform frequency response for single parts of machine tool structures, because increasing stiffness parameters of single part can no lead automatically to improve stiffness of whole machine. At Fig.4 is shown comparison of dynamic stiffness two CNC machine with same kinematic configuration. Traditional machine structure composed of gray cast iron parts (blue) is compared with new steel-concrete composite parts.

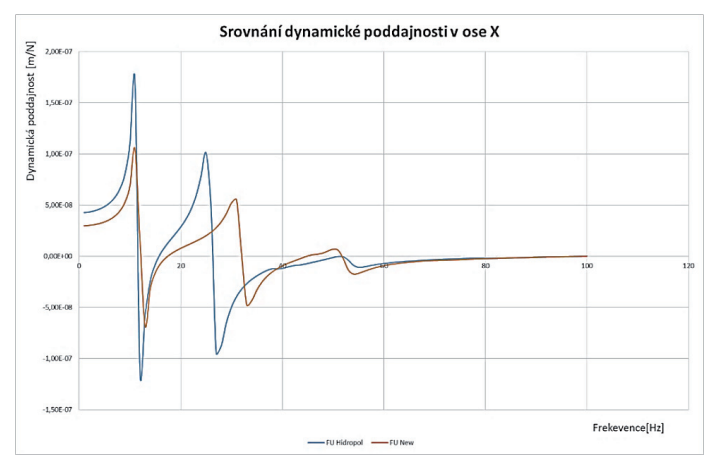

Fig. 4: Dynamic compliance comparing.

\section{Conclusions}

Special steel-concrete composite material have been developed and have been implemented to heavy CNC machining center with moveable column. All parts of machine frame were optimized primarily to improve static and dynamic parameters. Modal analysis were performed to compare welded steel structure of machine bed before filling with high strength concrete and after filling. Graphs shown many natural frequencies of higher values were damped and peaks at lower frequencies is moved right. This fact indicates high stiffness of part and weight optimization. Most valuable analysis of machine tool - dynamic stiffness was realized too. Machine supporting structure containing parts of gray cast iron was compared with new solutions mentioned at previous section. It is possible to see that dynamic stiffness is higher for steel-concrete composite machine structures. System of parts made of composite bring out better damping properties. Finally it is desirably determine, that steel-concrete composite material is one of the best choice to reach better dynamic parameters of CNC machine tools in cost efficient way.

\section{References and Notes}

[1] Möhring, H., Brecher, C., Abele, E., Fleischer, J., \& Bleicher, F. (2015). Materials in machine tool structures. CIRP Annals Manufacturing Technology, 64(2), 725-748.

[2] MAREK, J., et al. Design of CNC Machine Tools. 1 nd ed. Praha: MM publishing, s.r.o., 2015. 727 p. ISBN 978-80-260-8637-6.

[3] Munirathnam M (2008) Einfluss masseoptimierter Kragarmstrukturen auf die dynamische Bahngenauigkeit von HSCFra“smaschinen, TU Darmstadt, Darmstadt. (Dr. -Ing. Dissertation).

[4] Altintas Y, Brecher C, Weck M, Witt S (2005) Virtual Machine Tool. Annals of the CIRP 54(2):651-674

[5] DEMEČ, P.: Ausgewählte Berechnungen der Werkzeugmaschinenproduktivität. In: Technológ. Roč. 5, č. 3 (2013), s. 2528. ISSN 1337-8996

\section{Biographical notes}

Ing. Dominik Hermanský, (1989). I received M.S. degree in mechanical engineering - product machines, systems and robotics from Brno University of Technology, (zech republic in 2014. I am a Ph. D. student in Design and Process Engineering at Brno University of Technology. Concurrently I am engaged in research organization Intemac Solutions. My research interests include creating advanced numerical models. Models predict static, dynamic and thermal behavior of machine tools. By using models next area of activity is designing of machine 
tools structures for new prototypes and optimization frames for current machines.

prof. Dr. Ing. Jiri Marek, (1964). Prof. Dr. Ing. Jiř Marek (1964), professor in Design and Process Engineering (since 2008) at Brno University of Technology (BUT). Graduate BUT in 1987, PhD defended at BUT (1996), to associate professor habilitated on BUT in 2004. Technical director TOSHULIN (2000-2014), Technical director KSK Kurim (2014-2016), now Technical director TOS Kurim and CKD Blansko. Member of Scientific council TU-VSB Ostrava, Faculty of Mechanical Engineering, Member of Management Board of MM Science Journal. Research interests of machine tools construction, engineering design science, virtual prototyping, and precision machine tools. Main author of the monograph "Design of CNC Machine Tools" (Praha: MM Publishing 2015), and over 130 scientific and professional articles in journals and contributions to scientific and professional conferences 